\title{
Clinical Responses and Synovial Vascularity in Obese Rheumatoid Arthritis Patients Treated with Adalimumab and Methotrexate
}

\author{
Gurjit S. Kaeley, Daryl K. MacCarter, Aileen L. Pangan, Xin Wang, Jasmina Kalabic, \\ and Veena K. Ranganath
}

\begin{abstract}
Objective. Obese patients with rheumatoid arthritis (RA) report more joint swelling and tenderness and often have poorer responses to therapy than nonobese patients. The aim of this posthoc analysis of the MUSICA trial was to compare imaging and clinical disease activity measures in obese and nonobese patients with RA.

Methods. MUSICA evaluated methotrexate (MTX) $20 \mathrm{mg} /$ week versus $7.5 \mathrm{mg} /$ week in combination with adalimumab (ADA) in RA patients with an inadequate response to MTX. Patients were categorized by baseline body mass index as normal $(<25)$, overweight $(\geq 25$ to $<30)$, or obese $(\geq 30)$. Synovial vascularity and hypertrophy, swollen and tender joint counts (SJC and TJC), American College of Rheumatology (ACR) responses, and low disease activity (LDA), defined as Clinical Disease Activity Index $<10$ and 28-joint count Disease Activity Score using C-reactive protein (DAS28-CRP) $<3.2$, were assessed at weeks 12 and 24.

Results. Patient characteristics were similar among groups at baseline. Obese patients had numerically smaller changes from baseline to weeks 12/24 in SJC, TJC, DAS28-CRP, and synovial hypertrophy and vascularity versus nonobese patients. Significantly fewer obese patients reached ACR20/50 at weeks 12 and 24, and LDA at Week 12; this difference was especially apparent in patients receiving $7.5 \mathrm{mg} /$ week MTX but was no longer significant at Week 24.

Conclusion. Obese patients with RA had worse clinical and ultrasonographic responses than nonobese patients, which were partly overcome with time. Obese patients may experience better and faster clinical improvements if ADA is initiated with high-dose $(20 \mathrm{mg} / \mathrm{week})$ rather than low-dose MTX. [ClinicalTrials.gov: NCT01185288] (First Release September 1 2018; J Rheumatol 2018;45:1628-35; doi:10.3899/jrheum.171232)
\end{abstract}

Key Indexing Terms: ADALIMUMAB

OBESITY

From the Division of Rheumatology and Clinical Immunology, University of Florida College of Medicine, Jacksonville, Florida; Department of Rheumatology, North Valley Hospital, Whitefish, Montana; Global Medical Affairs, AbbVie Inc., North Chicago, Illinois; Data and Statistical Sciences, AbbVie Inc., North Chicago, Illinois; Division of Rheumatology, University of California at Los Angeles, Los Angeles, California, USA; Pharmaceutical Development, AbbVie Deutschland GmbH \& Co. KG, Ludwigshafen, Germany.

This study was funded by AbbVie Inc., which manufactures adalimumab. GSK received research funds from AbbVie. VKR received grants from Bristol-Myers Squibb, Genentech, Mallinckrodt, Pfizer, and Rheumatology Research Foundation. DKM is a consultant and has served as a principal investigator for AbbVie. ALP, XW, and JK are AbbVie employees and may hold AbbVie stock or stock options.

G.S. Kaeley, MD, Division of Rheumatology and Clinical Immunology, University of Florida College of Medicine; D.K. MacCarter, MD, Department of Rheumatology, North Valley Hospital; A.L. Pangan, MD, Immunology Clinical Development, AbbVie Inc.; X. Wang, PhD, Data and Statistical Sciences, AbbVie Inc.; J. Kalabic, MD, Pharmaceutical Development, AbbVie Deutschland GmbH \& Co. KG; V.K. Ranganath, $M D$, Division of Rheumatology, University of California at Los Angeles. Address correspondence to Dr. V.K. Ranganath, UCLA Division of Rheumatology, Rehabilitation Building, 1000 Veteran Avenue, Rm 32-59, University of California at Los Angeles, Los Angeles, California 90095, USA.E-mail:vranganath@mednet.ucla.edu

Accepted for publication April 20, 2018.
The prevalence of obesity has risen worldwide over the past 2 decades ${ }^{1}$. Because adipose tissue may independently contribute to systemic inflammation and release mediators of inflammation ${ }^{2,3,4}$, patients with rheumatoid arthritis (RA) who are overweight or obese may have elevated levels of inflammatory cytokines, such as interleukin (IL-) 6 and tumor necrosis factor (TNF)- $\alpha$, beyond those attributable to $\mathrm{RA}^{4,5}$. A recent study also demonstrated greater body mass index (BMI) was associated with higher C-reactive protein (CRP) and erythrocyte sedimentation rate (ESR) in female patients with RA. These markers of inflammation were significantly higher among women with severe obesity (BMI $\geq 35 \mathrm{~kg} / \mathrm{m}^{2}$ ) compared with women with normal $\mathrm{BMI}^{6}$. Obese patients with RA may also have poorer outcomes, and it has been reported that obese patients do not respond as well to treatment with corticosteroids or anti-TNF agents compared with nonobese patients with $\mathrm{RA}^{7,8,9,10}$.

Obesity is associated with a higher likelihood of pain and chronic pain syndromes ${ }^{11,12}$ and could present a barrier to the accuracy of clinical examination and patient-reported outcomes. Radiographic measures in obese patients show less

Personal non-commercial use only. The Journal of Rheumatology Copyright @ 2018 . All rights reserved. 
joint damage than in patients with normal $\mathrm{BMI}^{13,14,15}$, suggesting that clinical measures of swollen joints may not accurately represent true synovitis, and clinical overestimation may be confounding the scores. This was evident in a recent study that demonstrated that joint synovitis in obese patients was overestimated by clinical measures ${ }^{16}$. Musculoskeletal ultrasound (US) has demonstrated higher sensitivity than clinical measures in identifying synovitis ${ }^{17}$ and can assess synovial hypertrophy and vascularity of the pannus $^{18}$. Thus, US may present an additional tool to aid in detection of joint inflammation in obese patients with RA. However, data in this area are limited.

The MUSICA trial assessed clinical and ultrasonographic outcomes in patients with RA who had an inadequate response to methotrexate (MTX) and initiated adalimumab (ADA) treatment in combination with low- or high-dose MTX $^{19,20}$. The objective of this posthoc analysis of data from the MUSICA trial was to provide a better understanding of the utility of US in the clinical management of obese patients with RA by comparing clinical and imaging disease activity measures and treatment responses in obese and nonobese patients. The effect of low- and high-dose MTX was also assessed.

\section{MATERIALS AND METHODS}

Patients and studies. MUSICA (ClinicalTrials.gov: NCT01185288) was a phase IV, double-blind, randomized trial in patients with moderate to severe RA and an inadequate response to MTX ( $\geq 15 \mathrm{mg} /$ week MTX for $\geq 12$ weeks $)^{19}$. Patients were randomized to initiate treatment with open-label, subcutaneous ADA $40 \mathrm{mg}$ every other week in combination with double-blind, oral MTX $7.5 \mathrm{mg} /$ week (low dose) or $20 \mathrm{mg} /$ week (high dose) for 24 weeks ${ }^{19}$. This study was conducted in the United States, including Puerto Rico, in accordance with the protocol of the International Conference on Harmonisation, and ethical principles from the Declaration of Helsinki. The study was approved by the ethics review board of the main institution (Western Institutional Review Board; date of approval: September 24, 2010; ethics approval/site number: W170359577) and ethics review boards of each additional center that participated in the study, and all patients provided written informed consent.

Clinical and US assessments and statistical analysis. Data as observed were used for these analyses; last observation carried forward was examined for most of the analyses for sensitivity. Patients were grouped according to baseline BMI into 3 groups: normal (BMI $<25 \mathrm{~kg} / \mathrm{m}^{2}$ ), overweight (BMI $\geq 25$ to $<30 \mathrm{~kg} / \mathrm{m}^{2}$ ), and obese (BMI $\geq 30 \mathrm{~kg} / \mathrm{m}^{2}$ ). Inclusion and exclusion criteria have been described previously ${ }^{19}$. These variables were assessed at weeks 12 and 24: swollen joint count for 66 joints (SJC66), tender joint count for 68 joints (TJC68), 28-joint count Disease Activity Score using CRP (DAS28-CRP), and number of patients achieving low disease activity (LDA), defined as DAS28-CRP $<3.2$ or Clinical Disease Activity Index $(\mathrm{CDAI}) \leq 10$, and $20 \%$ or $50 \%$ improvement in the American College of Rheumatology criteria (ACR20/50). Quality of life in the BMI groups was evaluated with the Medical Outcomes Study Short Form-36 (SF-36) physical and mental component summaries (PCS and MCS), and physical function was assessed using the Health Assessment Questionnaire-Disability Index (HAQ-DI) at weeks 12 and 24.

US was used to assess changes in synovial hypertrophy and synovial vascularity, and these data have been previously published ${ }^{20}$. Briefly, synovial vascularity and hypertrophy were measured by power Doppler and greyscale, respectively, bilaterally at metacarpophalangeal joints 2, 3, and 5; metatarsophalangeal joint 5; and wrists using Esaote MyLab 5 machines
(Esaote North America Inc.), with settings in the same range. Images were deidentified and scored centrally. A semiquantitative scoring system (range 0-3) incorporating Outcome Measures in Rheumatology (OMERACT) definitions was used to measure synovial vascularity ${ }^{21}$. Greyscale images were scored on a scale of 0 to 3 .

The correlation between SJC66 or TJC68 and synovial vascularity or synovial hypertrophy at baseline, Week 12 , and Week 24 were assessed by Pearson correlation coefficients. The correlations between swelling or tenderness and synovial vascularity or synovial hypertrophy at baseline, Week 12, and Week 24 were also assessed at each individual joint by Spearman's correlation coefficients. The chi-square test was used for categorical variables; analysis of covariance adjusting for baseline, treatment, and BMI group was used for continuous variables. Additional analyses were performed to adjust for baseline covariates. Logistic regression analysis was used to assess effect of BMI group on ACR 20/50 response at weeks 12 and 24, and mixed effects linear regression analysis was used to assess effect of BMI group on DAS28-CRP, CDAI, synovial vascularity, and synovial hypertrophy at weeks 12 and 24. A number of covariates were tested for inclusion in the models, including baseline age, race, sex, disease activity (DAS28-CRP, CDAI, and Simplified Disease Activity Index), rheumatoid factor, anticyclic citrullinated peptide seropositivity, prior use of biologic and conventional synthetic disease-modifying antirheumatic drug (DMARD), SJC66, TJC68, duration of RA, US hypertrophy and vascularity, smoking status, and BMI. Stepwise variable selection of the covariates was used for the regression analyses.

\section{RESULTS}

Baseline disease characteristics of patients in the $3 \mathrm{BMI}$ groups. Overall, 309 patients were enrolled in MUSICA; 1 patient did not have BMI data at baseline and was excluded from this analysis. Of the 308 patients included in this analysis, 69 patients $(22.4 \%)$ were in the normal BMI group, 102 patients $(33.1 \%)$ were in the overweight BMI group, and 137 patients $(44.5 \%)$ were in the obese group at baseline. No significant differences were observed in baseline disease characteristics and US disease assessments between the 3 BMI groups, with the exception of SF-36 MCS ( $p<0.033$; Table 1). In the normal and overweight groups, men had numerically higher mean CRP levels at baseline compared with women (18.9 vs $10.1 \mathrm{mg} / \mathrm{l}$ and 21.7 vs $14.6 \mathrm{mg} / \mathrm{l}$, respectively). In contrast, in the obese group, women had slightly higher mean CRP levels compared with men (14.9 vs 11.5 $\mathrm{mg} / \mathrm{l})$. However, differences by BMI group and sex were not significant $(\mathrm{p}=0.139)$.

Clinical and functional outcomes in patients in the $3 \mathrm{BMI}$ groups at 12 and 24 weeks. Compared with patients in the normal and overweight categories, significantly fewer obese patients taking the concomitant low-dose MTX (7.5 mg/week) reached ACR20 and ACR50 at weeks 12 and 24 and CDAI LDA at Week 12; the difference for CDAI LDA was no longer significant by Week 24 (Figure 1). Similar, but not significant, findings were observed when LDA was defined by DAS28-CRP. When assessed for quality of life and physical function outcomes, patients in the overweight and obese groups had numerically higher HAQ-DI and lower SF-36 PCS scores at weeks 12 and 24, indicating greater disability/physical limitations, and numerically smaller improvements from baseline in HAQ-DI compared with

Personal non-commercial use only. The Journal of Rheumatology Copyright @ $\odot 2018$. All rights reserved 
Table 1. Baseline disease characteristics of patients in the normal, overweight, and obese BMI categories.

\begin{tabular}{lcccc}
\hline Characteristics & $\begin{array}{c}\text { Normal }(\mathrm{BMI} \\
<25), \mathrm{n}=69\end{array}$ & $\begin{array}{c}\text { Overweight }(\mathrm{BMI} \geq 25 \text { to } \\
<30), \mathrm{n}=102\end{array}$ & $\begin{array}{c}\text { Obese }(\mathrm{BMI} \\
\geq 30), \mathrm{n}=137\end{array}$ & $\mathrm{p}^{\diamond}$ \\
\hline Female, $\mathrm{n}(\%)$ & $46(67)$ & $77(75)$ & $108(79)$ & \\
SJC66 & $19.0(13.3)$ & $18.2(10.6)$ & $18.2(9.8)$ & 0.862 \\
SJC28 & $13.0(6.0)$ & $12.3(5.8)$ & $11.8(5.5)$ & 0.358 \\
TJC68 & $30.0(17.6)$ & $29.8(16.1)$ & $33.0(17.4)$ & 0.268 \\
TJC28 & $16.2(7.3)$ & $15.8(7.2)$ & $16.5(7.2)$ & 0.763 \\
CRP, mg/l & $13.0(22.5)$ & $16.3(25.3)$ & $14.2(17.3)$ & 0.583 \\
Female & $10.1(18.3)$ & $14.6(22.9)$ & $14.9(18.9)$ & \\
Male & $18.9(28.7)$ & $21.7(31.2)$ & $11.5(9.1)$ & \\
DAS28-CRP* & $5.8(1.0)$ & $5.8(1.0)$ & $5.9(0.9)$ & 0.762 \\
CDAI & $41.9(13.5)$ & $40.2(13.5)$ & $41.0(12.2)$ & 0.692 \\
HAQ-DI & $1.4(0.6)$ & $1.5(0.6)$ & $1.5(0.6)$ & 0.288 \\
Synovial hypertrophy & $34.6(7.4)$ & $34.0(7.4)$ & $33.1(7.2)$ & 0.346 \\
$\quad$ Median (range) & $35.0(8.0-46.0)$ & $35.0(1.5-47.5)$ & $34.5(6.0-45.0)$ & \\
Synovial vascularity & $6.1(5.5)$ & $6.5(6.0)$ & $5.2(4.8)$ & 0.143 \\
$\quad$ Median (range) & $5.5(0.0-26.5)$ & $5.0(0.0-25.0)$ & $4.0(0.0-25.5)$ & \\
SF-36 PCS & $33.3(8.4)$ & $31.7(9.1)$ & $30.6(8.0)$ & 0.113 \\
SF-36 MCS & $44.1(13.2)$ & $45.6(11.9)$ & $41.3(13.1)$ & 0.033 \\
\hline
\end{tabular}

Observed data are reported. Data are mean (SD) unless indicated otherwise. ${ }^{\diamond} \mathrm{P}$ value for differences between groups from 1-way ANOVA. * Overweight group, $\mathrm{n}=100$; obese group, $\mathrm{n}=133$. $\dagger$ Overweight group, $\mathrm{n}=100$; obese group, $\mathrm{n}=132 .{ }^{\ddagger}$ Overweight group, $\mathrm{n}=101$; obese group, $\mathrm{n}=$ 135. ${ }^{\S}$ Normal group, $\mathrm{n}=68$; overweight group, $\mathrm{n}=100$; obese group, $\mathrm{n}=134$. BMI: body mass index; CDAI: Clinical Disease Activity Index; CRP: C-reactive protein; DAS28-CRP: 28-joint count Disease Activity Score using CRP; HAQ-DI: Health Assessment Questionnaire-Disability Index; MCS: mental component summary; PCS: physical component summary; SF-36: Medical Outcomes Study Short Form-36; SJC66: swollen joint count at 66 joints; SJC28: SJC at 28 joints; TJC68: tender joint count at 68 joints; TJC28: TJC at 28 joints.

patients in the normal BMI group (data not shown). No trends were apparent for SF-36 MCS across the BMI groups. After 12 and 24 weeks of treatment with ADA in combination with low- or high-dose MTX, obese patients tended to have numerically smaller mean changes from baseline in SJC66, TJC68, DAS28-CRP, and CDAI compared with patients in the normal and overweight categories (Supplementary Figure 1 , available with the online version of this article). The clinical outcomes in the low-dose MTX patients showed a numerical trend toward lower response with increasing BMI, with no statistically significant differences observed.

US outcomes and correlation with clinical outcomes in patients in the BMI groups. Compared with patients in the normal and overweight categories, obese patients who received low-dose MTX had significantly less improvement from baseline to weeks 12 and 24 in synovial hypertrophy $(\mathrm{p}=0.002$ and $\mathrm{p}=0.03$, respectively) and numerically smaller changes in synovial vascularity (Figure 2). No significant differences in improvement from baseline by BMI group were observed in the patients who received high-dose MTX.

The Pearson correlations were low between overall synovial vascularity or hypertrophy scores and clinical findings of swelling and tenderness for 28 joints in all 3 BMI groups at baseline, Week 12, and Week 24. At the individual joint level, the most consistent and significant correlation between clinical joint swelling and synovial vascularity was observed at the wrist joint in the normal BMI group at baseline, Week 12, and Week $24(0.313-0.376, \mathrm{p}<0.01)$; no consistent and significant correlations were found for the overweight and obese BMI groups. The difference in the SJC between all BMI groups was also significant only at the wrist at all 3 timepoints. The proportion of patients with no synovial vascularity in the 3 BMI groups at weeks 12 and 24 was not statistically different.

Regression analysis adjusted for baseline covariates. Logistic regression analysis adjusted for baseline covariates showed that obese patients who received low-dose MTX had significantly lower probability of achieving ACR20 response compared with patients in the normal and overweight BMI groups at weeks 12 and 24 (Figure 3A and 3C). Similar results were observed with the ACR50 response (Figure 3B and 3D). A similar numerical trend was also observed in a mixed effect linear regression model for CDAI, DAS28-CRP, and synovial hypertrophy and vascularity (Supplementary Table 1, available with the online version of this article); obese patients who received low-dose MTX had significantly higher CDAI scores at Week 24 and less improvement in synovial hypertrophy at weeks 12 and 24 ( $<<0.05$ for all) versus patients in the overweight group. Differences were not significant for the obese versus normal BMI groups. Patients who received high-dose MTX did not have significant differences in probability of achieving ACR20 or ACR50 response

Personal non-commercial use only. The Journal of Rheumatology Copyright ()$_{2018}$. All rights reserved. 
ACR20
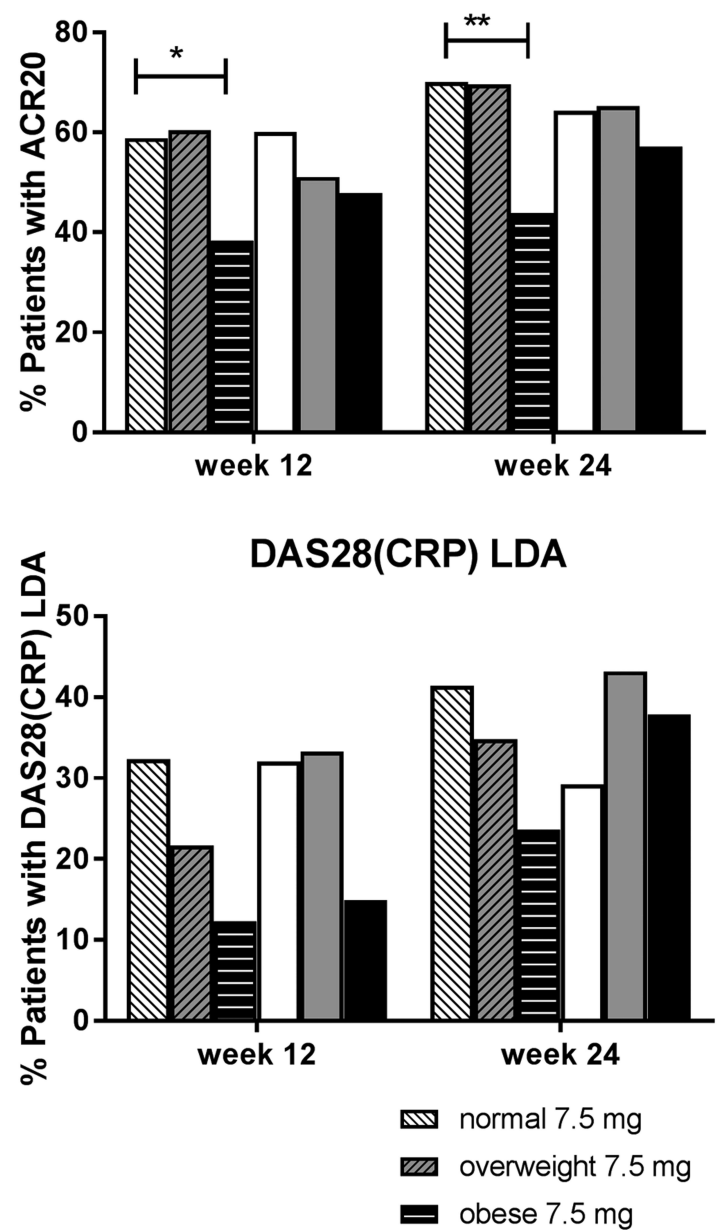

ACR50

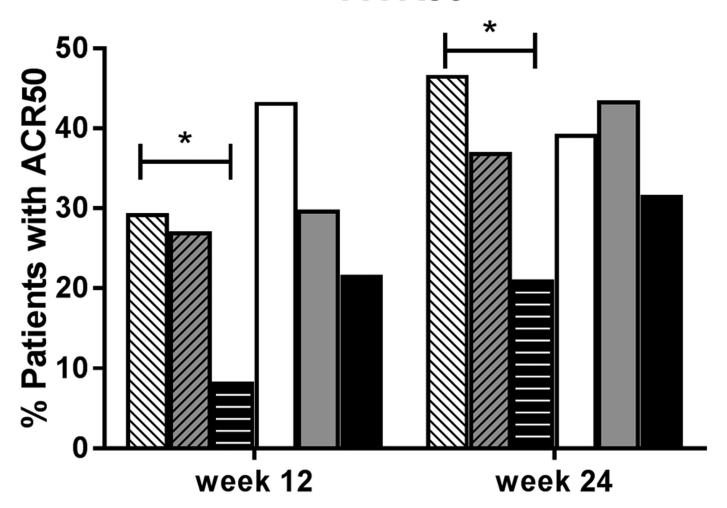

CDAI LDA

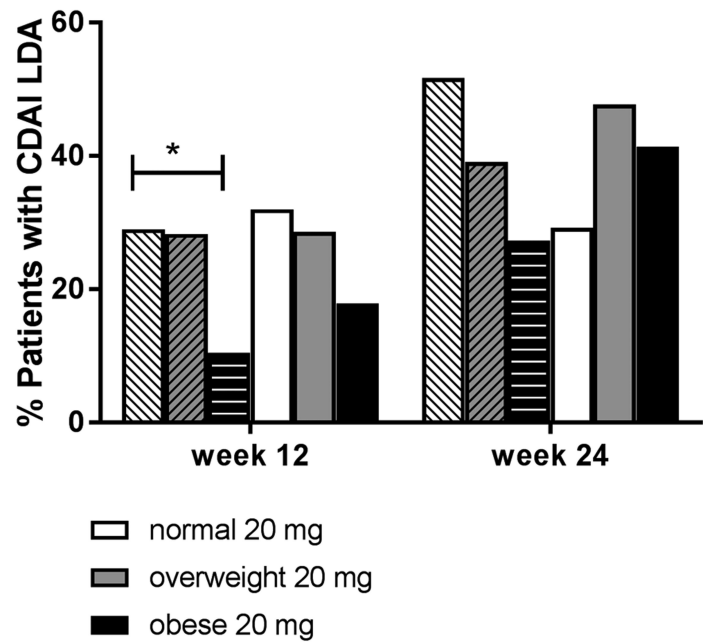

Figure 1. Proportions of patients in the 3 BMI groups achieving $20 \%$ or $50 \%$ improvement in ACR scores or DAS28-CRP LDA or CDAI LDA at weeks 12 or 24 . Observed data. Dosage refers to methotrexate/week. P values for comparison between BMI groups: * p $<0.05$; ** $\mathrm{p}<0.01$ using chi-square test. ACR20/50: American College of Rheumatology criteria for $20 \%$ improvement $/ 50 \%$ improvement; BMI: body mass index; DAS28-CRP: 28-joint count Disease Activity Score based on C-reactive protein; CDAI: Clinical Disease Activity Index; LDA: low disease activity.

(Figure 3) or CDAI, DAS28-CRP, and synovial hypertrophy and vascularity assessments at weeks 12 and 24 (Supplementary Table 1) in any of the BMI group comparisons, except for DAS28-CRP at Week 12, which was significantly lower in patients with normal BMI versus patients in the obese group $(\mathrm{p}<0.05)$. These results are consistent with the results of the logistic regression analysis.

\section{DISCUSSION}

The MUSICA trial demonstrated that significantly fewer obese patients with RA who initiated ADA with concomitant low-dose MTX (7.5 mg/week) achieved ACR20, ACR50, and CDAI LDA responses, and a numerically smaller number achieved a DAS28-CRP LDA response at Week 12 compared with patients in the normal and overweight categories. However, these effects were less pronounced by Week 24 . Further, obese patients with RA who received concomitant low-dose MTX also had significantly less improvement in synovial hypertrophy, although the improvements in synovial vascularity were not statistically different compared with the overweight and normal BMI groups. These differences between BMI groups were less apparent in patients who received a concomitant MTX dose of $20 \mathrm{mg}$ /week.

Based on a previous study, obese patients with RA may have poorer outcomes than patients with normal weight ${ }^{7}$. Our results of the MUSICA trial showed a similar trend and suggest that overweight and obese patients in the low MTX group, but not in the high MTX group, may have less improvement in clinical disease activity compared with patients in the normal BMI group. Further, obese patients had less improvement in synovial hypertrophy and vascularity, both of which are indicative of inflammatory activity in the joint and could be a precursor to joint damage. This is interesting considering the finding that obese patients have less

$$
\text { Personal non-commercial use only. The Journal of Rheumatology Copyright @ } 2018 \text {. All rights reserved. }
$$




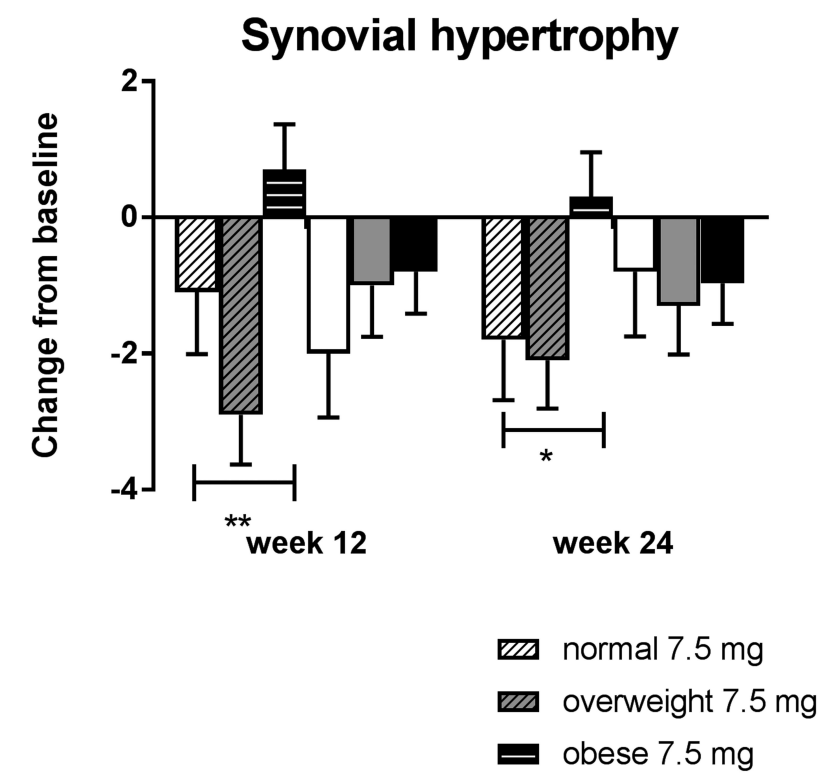

\section{Synovial hypertrophy}

Synovial vascularity

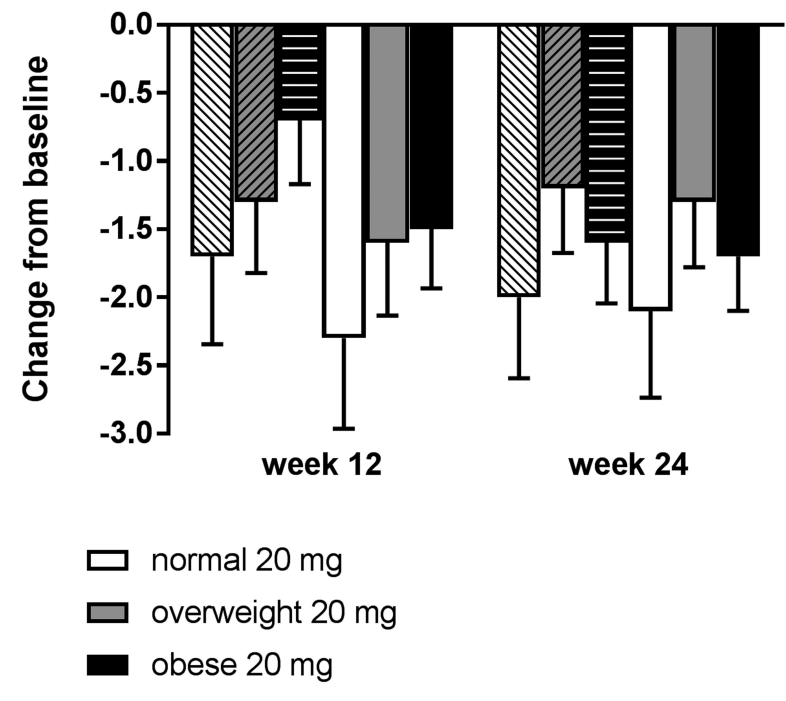

Figure 2. Mean change from baseline to weeks 12 and 24 in synovial hypertrophy and synovial vascularity per BMI group. Dosage refers to methotrexate/week. P values for comparison between BMI groups: * $\mathrm{p}<0.05$; ** $\mathrm{p}<0.01$. ANCOVA adjusting for baseline, treatment, and BMI group was used for continuous variables. BMI: body mass index.

radiographic progression than nonobese patients upon treatment with anti-TNF and synthetic DMARD ${ }^{13,14,15}$. In general, synovial vascularity and hypertrophy did not correlate well with joint swelling or tenderness, regardless of BMI, indicating that the US assessments offered an advantage as a more accurate reflection of true synovitis. These results suggest that musculoskeletal US is effective for evaluating response in obese patients with RA; further studies are required to confirm this. Of note, the MUSICA trial analyzed the role of US imaging only and no radiographic data were collected; therefore, the correlation of US changes with subsequent radiographic progression could not be evaluated in this analysis.

Because of the high prevalence of obesity in the general population, treatment outcomes and disease management in obese patients are of interest. Obesity is associated with increased recruitment of macrophages and other immune cells $^{22,23,24}$ as well as expression of inflammatory cytokines, including IL-6 and TNF- $\alpha$, which may result in a systemic

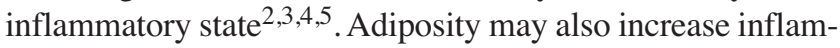
matory markers (CRP and ESR) independently of RA activity, especially among obese women ${ }^{6}$. This may explain our findings that female patients in the obese group (BMI $\geq 30 \mathrm{~kg} / \mathrm{m}^{2}$ ) had slightly higher mean CRP levels compared with women with normal weight, whereas CRP levels were lower in obese men compared with men in the normal and overweight groups.

Our data are also consistent with previous cohort and registry studies that have demonstrated less improvement after treatment with anti-TNF agents among patients with a higher
BMI compared with patients with a normal $\mathrm{BMI}^{8,9,25}$. Although BMI does not seem to influence trough levels of anti-TNF agents, a trend toward a lower ADA trough level was observed with a BMI > 30 among patients with inflammatory bowel disease ${ }^{26}$. Increased body weight has been reported to be associated with increased clearance of both $\mathrm{ADA}^{27}$ and $\mathrm{MTX}^{28}$, although significant intersubject variability in the pharmacokinetics of each drug is also reported. Further, in the CONCERTO trial, ADA concentration decreased with increased body weight ${ }^{29}$. However, because MTX was shown to reduce ADA clearance by $44 \%$ in patients with RA receiving multiple doses of ADA $(40 \mathrm{mg}$ every other week), resulting in mean steady-state ADA trough concentrations of about $5 \mu \mathrm{g} / \mathrm{ml}$ (without MTX) and 8-9 $\mu \mathrm{g} / \mathrm{ml}$ (with MTX), it is unclear whether ADA clearance is also affected with increasing body weight when it is co-administered with MTX $^{30}$. Overall, further studies are needed to obtain these results and to determine whether obesity directly leads to worsened outcomes in patients with RA, or whether these outcomes are associated with the suboptimal doses of ADA and/or MTX seen in heavy patients.

The accumulation of intracellular MTX polyglutamate (MTX-PG) chains has been found to affect the efficacy of treatment in $\mathrm{RA}^{31,32,33}$. BMI was demonstrated to have a significant effect on MTX-PG accumulation in a recent study in a Japanese population; MTX-PG levels were significantly higher in the normal BMI group versus the overweight BMI group $^{34}$. This may explain the better outcomes observed in nonobese versus obese patients in our study. MTX treatment was also associated with reduced levels of TNF- $\alpha$, IL- 6 , and

Personal non-commercial use only. The Journal of Rheumatology Copyright $@$ 2018. All rights reserved 


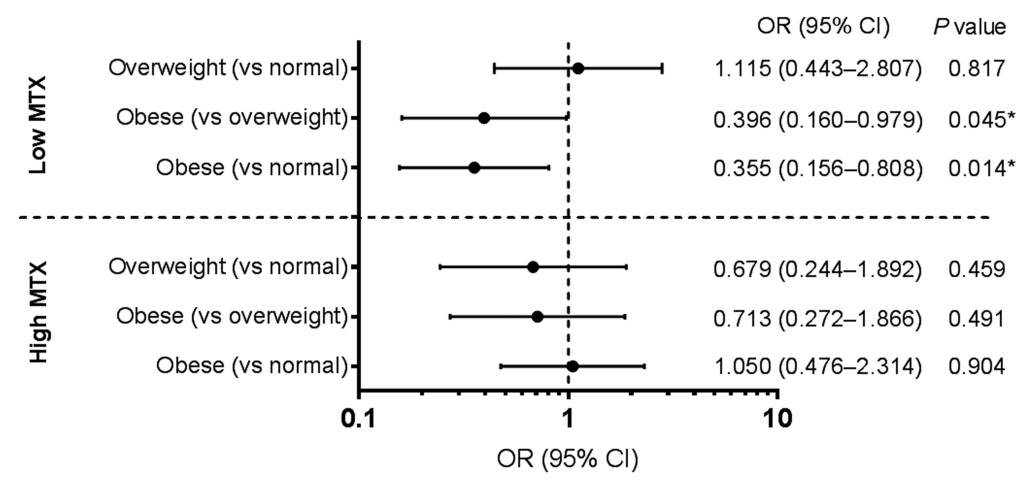

B

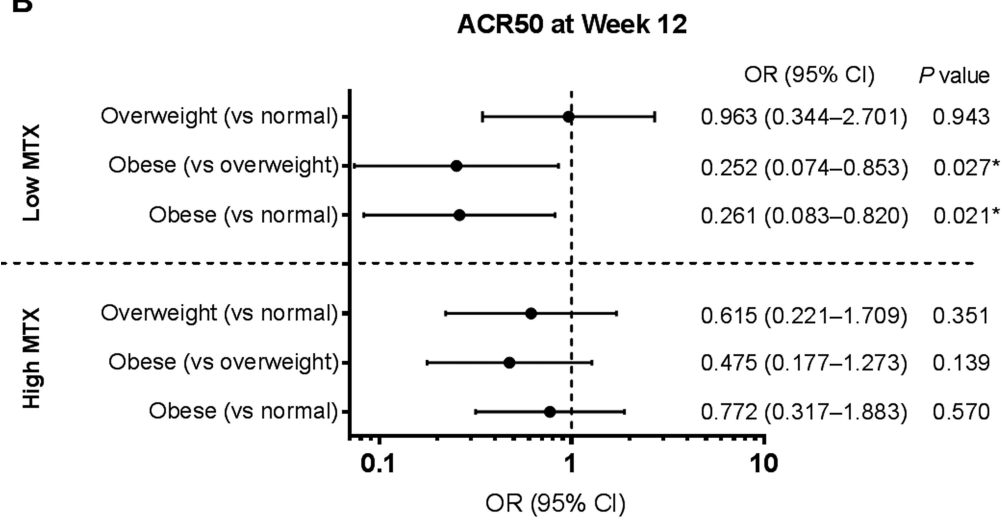

C

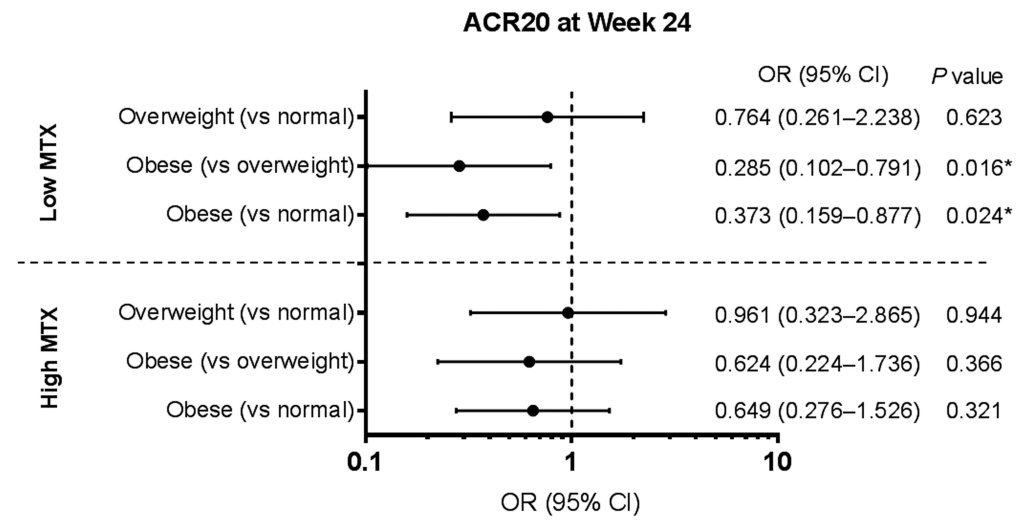

D

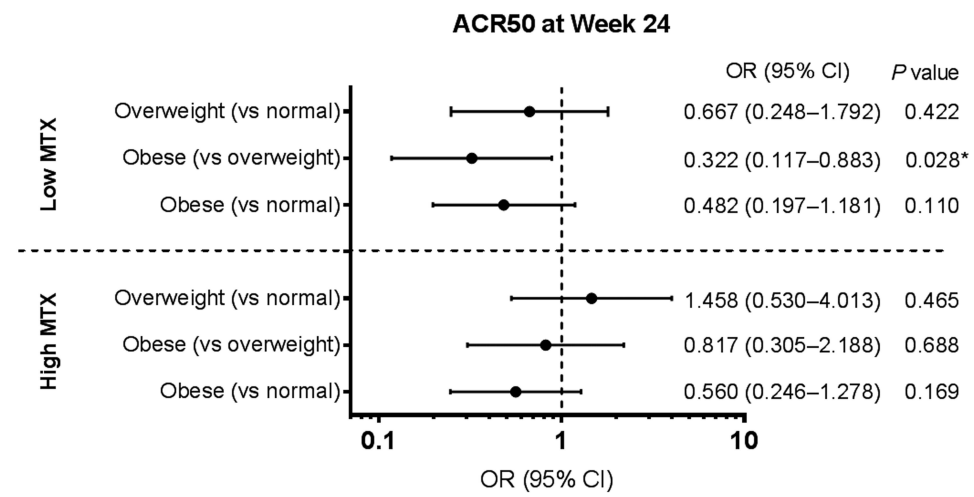

Figure 3. Logistic regression analysis of Week 12 (A) ACR20 and (B) ACR50 responses, and Week 24: (C) ACR20 and (D) ACR50 responses per BMI and MTX dose groups. BMI groups: normal (BMI $<25)$, overweight (BMI $\geq 25$ to $<30$ ), and obese $(B M I \geq 30)$. Observed data. $\mathrm{P}$ values for comparison between BMI groups: $* \mathrm{p}<0.05$. BMI and treatment and interaction were always included in the model to allow analyses by these factors. Selected covariates in the final models included CRP, SJC66, and TJC68 for the CDAI model; SJC66 and TJC68 for the DAS28-CRP model; anticyclic citrullinated peptide status, HAQ-DI, and synovial hypertrophy for the synovial hypertrophy model; and synovial vascularity for the synovial vascularity model. Stepwise selection of baseline covariates was performed with forward inclusion $p$ value cutoff of 0.1 and backward elimination $\mathrm{p}$ value cutoff of 0.05 from the following covariates: age, sex, race, rheumatoid factor, smoking status, anticyclic citrullinated peptide status, HAQ-DI, CRP (mg/l), physician's global assessment, patient's global assessment, patient assessment of pain, SJC66, TJC68, CDAI, DAS28-CRP, SDAI, ultrasound bony erosion, synovial hypertrophy, synovial vascularity, prior biologic DMARD, prior synthetic DMARD, prior NSAID, prior corticosteroid, baseline systemic corticosteroid use, prior MTX dose, BMI, and RA duration at first dose. ACR20/50: American College of Rheumatology criteria for $20 \% / 50 \%$ improvement; BMI: body mass index; CDAI: Clinical Disease Activity Index; CRP: C-reactive protein; DAS28-CRP: 28-joint count Disease Activity Score based on CRP; DMARD: diseasemodifying antirheumatic drug; HAQ-DI: Health Assessment Questionnaire-Disability Index; MTX: methotrexate; SDAI: Simplified Disease Activity Index; SJC66: swollen joint count at 66 joints; TJC68: tender joint count at 68 joints; NSAID: nonsteroidal antiinflammatory drug; RA: rheumatoid arthritis.

Personal non-commercial use only. The Journal of Rheumatology Copyright @ 2018 . All rights reserved. 
leptin in obese mice ${ }^{35}$. However, it is not known whether MTX reduces systemic cytokines in a dose-dependent manner in humans.

Limitations of our present study include the posthoc features of the analyses. The patients enrolled in the MUSICA study had established RA (mean \pm SD RA duration: $5.3 \pm 7.6 \mathrm{yrs})^{19}$, and it is not clear whether similar effects would be observed in patients with early RA. Also, patients in MUSICA received MTX at stable doses $\geq 15 \mathrm{mg} /$ week for 12 weeks prior to the study; it cannot be ruled out that the effects observed here might be affected in part by prior MTX dosing, especially the longer persisting MTX-PG derivatives. However, this posthoc analysis of the MUSICA dataset is of value because this trial evaluated a large US cohort of patients with RA.

The study design of MUSICA uniquely allowed us to use clinical and US measures to assess the effect of 2 doses of MTX concomitantly administered with ADA in patients who were of normal weight, overweight, or obese. Our data indicate that obese patients with RA had poorer clinical and synovial hypertrophy responses than nonobese patients and may have better clinical benefit if ADA is initiated with concomitant MTX at doses higher than $7.5 \mathrm{mg} /$ week.

\section{ACKNOWLEDGMENT}

AbbVie Inc. sponsored the study (NCT01185288), contributed to its design, participated in the collection, analysis, and interpretation of the data, and in the writing, reviewing, and approval of the final version. Medical writing support was provided by Naina Barretto, $\mathrm{PhD}$, of AbbVie, and Maria Hovenden, PhD, of Complete Publication Solutions LLC, and was financed by AbbVie. Clinical trial data can be requested from AbbVie through www.abbvie.com

\section{ONLINE SUPPLEMENT}

Supplementary material accompanies the online version of this article.

\section{REFERENCES}

1. Finucane MM, Stevens GA, Cowan MJ, Danaei G, Lin JK, Paciorek CJ, et al; Global Burden of Metabolic Risk Factors of Chronic Diseases Collaborating Group (Body Mass Index). National, regional, and global trends in body-mass index since 1980: systematic analysis of health examination surveys and epidemiological studies with 960 country-years and 9.1 million participants. Lancet 2011;377:557-67.

2. Neumann E, Frommer KW, Vasile M, Muller-Ladner U. Adipocytokines as driving forces in rheumatoid arthritis and related inflammatory diseases? Arthritis Rheum 2011;63:1159-69.

3. Hauner H. Secretory factors from human adipose tissue and their functional role. Proc Nutr Soc 2005;64:163-9.

4. Gremese E, Tolusso B, Gigante MR, Ferraccioli G. Obesity as a risk and severity factor in rheumatic diseases (autoimmune chronic inflammatory diseases). Front Immunol 2014;5:576.

5. Tzanavari T, Giannogonas P, Karalis KP. TNF-alpha and obesity. Curr Dir Autoimmun 2010;11:145-56.

6. George MD, Giles JT, Katz PP, England BR, Mikuls TR, Michaud $\mathrm{K}$, et al. The impact of obesity and adiposity on inflammatory markers in patients with rheumatoid arthritis. Arthritis Care Res 2017; 69:1789-98.

7. Ajeganova S, Andersson ML, Hafstrom I; BARFOT Study Group. Association of obesity with worse disease severity in rheumatoid arthritis as well as with comorbidities: a long-term followup from disease onset. Arthritis Care Res 2013;65:78-87.

8. Gremese E, Carletto A, Padovan M, Atzeni F, Raffeiner B, Giardina AR, et al; Gruppo Italiano di Studio sulle Early Arthritis (GISEA). Obesity and reduction of the response rate to anti-tumor necrosis factor alpha in rheumatoid arthritis: an approach to a personalized medicine. Arthritis Care Res 2013;65:94-100.

9. Heimans L, van den Broek M, le Cessie S, Siegerink B, Riyazi N, $\mathrm{Han} \mathrm{KH}$, et al. Association of high body mass index with decreased treatment response to combination therapy in recent-onset rheumatoid arthritis patients. Arthritis Care Res 2013;65:1235-42.

10. Liu Y, Hazlewood GS, Kaplan GG, Eksteen B, Barnabe C. Impact of obesity on remission and disease activity in rheumatoid arthritis: a systematic review and meta-analysis. Arthritis Care Res 2017;69:157-65.

11. Hitt HC, McMillen RC, Thornton-Neaves T, Koch K, Cosby AG Comorbidity of obesity and pain in a general population: results from the Southern Pain Prevalence Study. J Pain 2007;8:430-6.

12. Ursini F, Naty S, Grembiale RD. Fibromyalgia and obesity: the hidden link. Rheumatol Int 2011;31:1403-8.

13. Baker JF, Ostergaard M, George M, Shults J, Emery P, Baker DG, et al. Greater body mass independently predicts less radiographic progression on X-ray and MRI over 1-2 years. Ann Rheum Dis 2014;73:1923-8.

14. Westhoff G, Rau R, Zink A. Radiographic joint damage in early rheumatoid arthritis is highly dependent on body mass index. Arthritis Rheum 2007;56:3575-82.

15. Kaufmann J, Kielstein V, Kilian S, Stein G, Hein G. Relation between body mass index and radiological progression in patients with rheumatoid arthritis. J Rheumatol 2003;30:2350-5.

16. Bauer EM, Ben-Artzi A, Duffy EL, Elashoff DA, Vangala SS, Fitzgerald J, et al. Joint-specific assessment of swelling and power Doppler in obese rheumatoid arthritis patients. BMC Musculoskelet Disord 2017;18:99.

17. Brown AK, Quinn MA, Karim Z, Conaghan PG, Peterfy CG, Hensor E, et al. Presence of significant synovitis in rheumatoid arthritis patients with disease-modifying antirheumatic drug-induced clinical remission: evidence from an imaging study may explain structural progression. Arthritis Rheum 2006; 54:3761-73.

18. Kang T, Lanni S, Nam J, Emery P, Wakefield RJ. The evolution of ultrasound in rheumatology. Ther Adv Musculoskelet Dis 2012;4:399-411.

19. Kaeley GS, Evangelisto AM, Nishio MJ, Goss SL, Liu S, Kalabic J, et al. Methotrexate dosage reduction upon adalimumab initiation: clinical and ultrasonographic outcomes from the randomized noninferiority MUSICA trial. J Rheumatol 2016;43:1480-9.

20. Kaeley GS, Nishio MJ, Goyal JR, MacCarter DK, Wells AF, Chen $\mathrm{S}$, et al. Changes in ultrasonographic vascularity upon initiation of adalimumab combination therapy in rheumatoid arthritis patients with an inadequate response to methotrexate. Arthritis Rheumatol 2016;68:2584-92.

21. Backhaus M, Burmester GR, Gerber T, Grassi W, Machold KP, Swen WA, et al; Working Group for Musculoskeletal Ultrasound in the EULAR Standing Committee on International Clinical Studies including Therapeutic Trials. Guidelines for musculoskeletal ultrasound in rheumatology. Ann Rheum Dis 2001;60:641-9.

22. Mraz M, Haluzik M. The role of adipose tissue immune cells in obesity and low-grade inflammation. J Endocrinol 2014; 222:R113-27.

23. Ferrante AW Jr. The immune cells in adipose tissue. Diabetes Obes Metab 2013;15 Suppl 3:34-8.

24. Thomas D, Apovian C. Macrophage functions in lean and obese adipose tissue. Metabolism 2017;72:120-43.

25. Klaasen R, Wijbrandts CA, Gerlag DM, Tak PP. Body mass index

Personal non-commercial use only. The Journal of Rheumatology Copyright $\subset$ $\subset$ 2018. All rights reserved 
and clinical response to infliximab in rheumatoid arthritis. Arthritis Rheum 2011;63:359-64.

26. Bond A, Asher R, Jackson R, Sager K, Martin K, Kneebone A, et al. Comparative analysis of the influence of clinical factors including BMI on adalimumab and infliximab trough levels. Eur J Gastroenterol Hepatol 2016;28:271-6.

27. Ternant D, Ducourau E, Fuzibet P, Vignault C, Watier H, Lequerré $\mathrm{T}$, et al. Pharmacokinetics and concentration-effect relationship of adalimumab in rheumatoid arthritis. Br J Clin Pharmacol 2015;79:286-97.

28. Godfrey C, Sweeney K, Miller K, Hamilton R, Kremer J. The population pharmacokinetics of long-term methotrexate in rheumatoid arthritis. Br J Clin Pharmacol 1998;46:369-76.

29. Goss SL, Klein CE, Jin Z, Locke CS, Rodila RC, Kupper H, et al. Methotrexate dose in patients with early rheumatoid arthritis impacts methotrexate polyglutamate pharmacokinetics, adalimumab pharmacokinetics, and efficacy: pharmacokinetic and exposure-response analysis of the CONCERTO Trial. Clin Ther 2018:40:309-19.

30. Humira (adalimumab). Highlights of Information. [Internet. Accessed July 9, 2018.] Available from: www.rxabbvie.com/pdf/humira.pdf

31. Hornung N, Ellingsen T, Attermann J, Stengaard-Pedersen K, Poulsen JH. Patients with rheumatoid arthritis treated with methotrexate (MTX): concentrations of steady-state erythrocyte MTX correlate to plasma concentrations and clinical efficacy. J Rheumatol 2008;35:1709-15.
32. Dervieux T, Furst D, Lein DO, Capps R, Smith K, Caldwell J, et al. Pharmacogenetic and metabolite measurements are associated with clinical status in patients with rheumatoid arthritis treated with methotrexate: results of a multicentred cross sectional observational study. Ann Rheum Dis 2005;64:1180-5.

33. Dervieux T, Furst D, Lein DO, Capps R, Smith K, Walsh M, et al. Polyglutamation of methotrexate with common polymorphisms in reduced folate carrier, aminoimidazole carboxamide ribonucleotide transformylase, and thymidylate synthase are associated with methotrexate effects in rheumatoid arthritis. Arthritis Rheum 2004;50:2766-74.

34. Takahashi C, Kaneko Y, Okano Y, Taguchi H, Oshima H, Izumi K, et al. Association of erythrocyte methotrexate-polyglutamate levels with the efficacy and hepatotoxicity of methotrexate in patients with rheumatoid arthritis: a 76-week prospective study. RMD Open 2017;3:e00363.

35. DeOliveira CC, Acedo SC, Gotardo EM, Carvalho Pde O, Rocha T, Pedrazzoli J Jr, et al. Effects of methotrexate on inflammatory alterations induced by obesity: an in vivo and in vitro study. Mol Cell Endocrinol 2012;361:92-8. 